\title{
Organized Surface Functional Groups: Cooperative Catalysis Via Thiol/Sulfonic Acid Pairing
}

Eric L. Margelefsky ${ }^{l}$, Ryan K. Zeidan ${ }^{l}$, Véronique Dufaud ${ }^{2}$ and Mark E. Davis ${ }^{1, *}$ ${ }^{1}$ Division of Chemistry and Chemical Engineering, California Institute of Technology,

Pasadena CA 91125, ${ }^{2}$ Laboratoire de Chimie, Ecole Normale Supérieure de Lyon, 46 allee d'Italie, 69364 Lyon cedex 07, France

\section{Supporting Information}




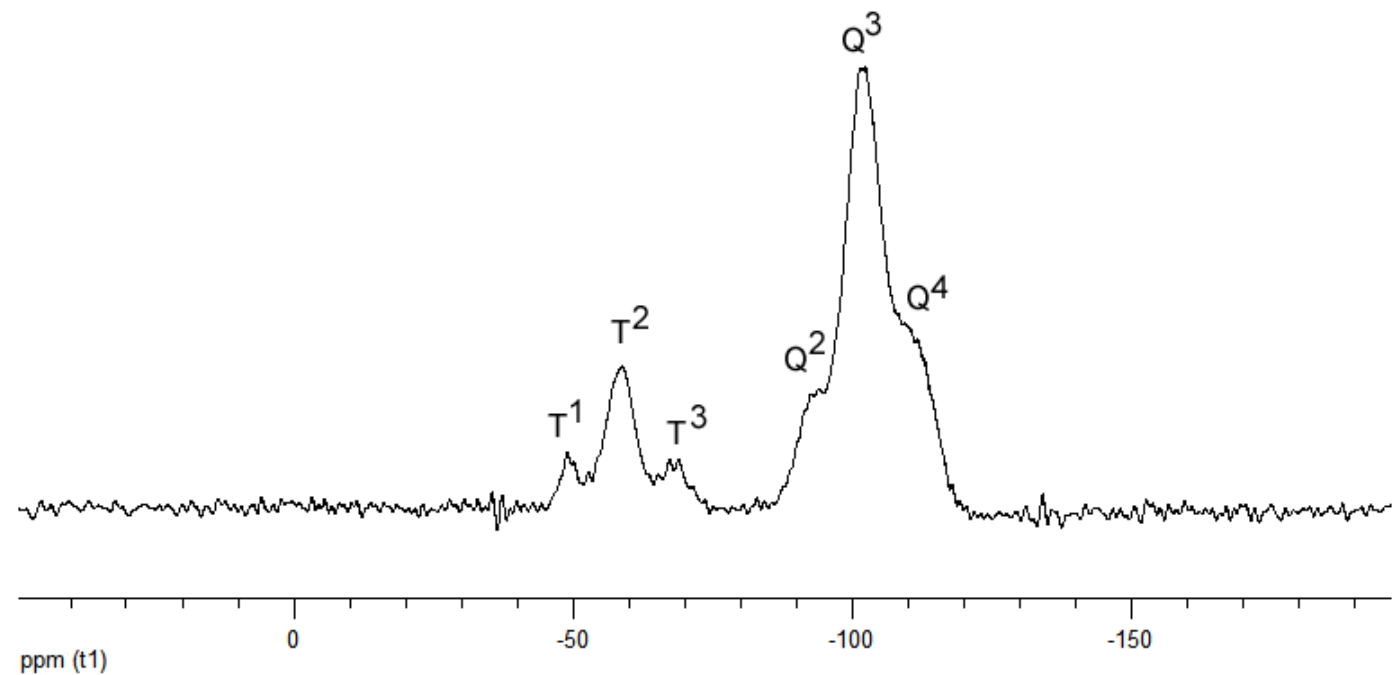

Figure S1. ${ }^{29} \mathrm{Si}$ CP/MAS NMR spectrum of SBA-g1 (loading $=0.7 \mathrm{mmol} / \mathrm{g}$ ) 


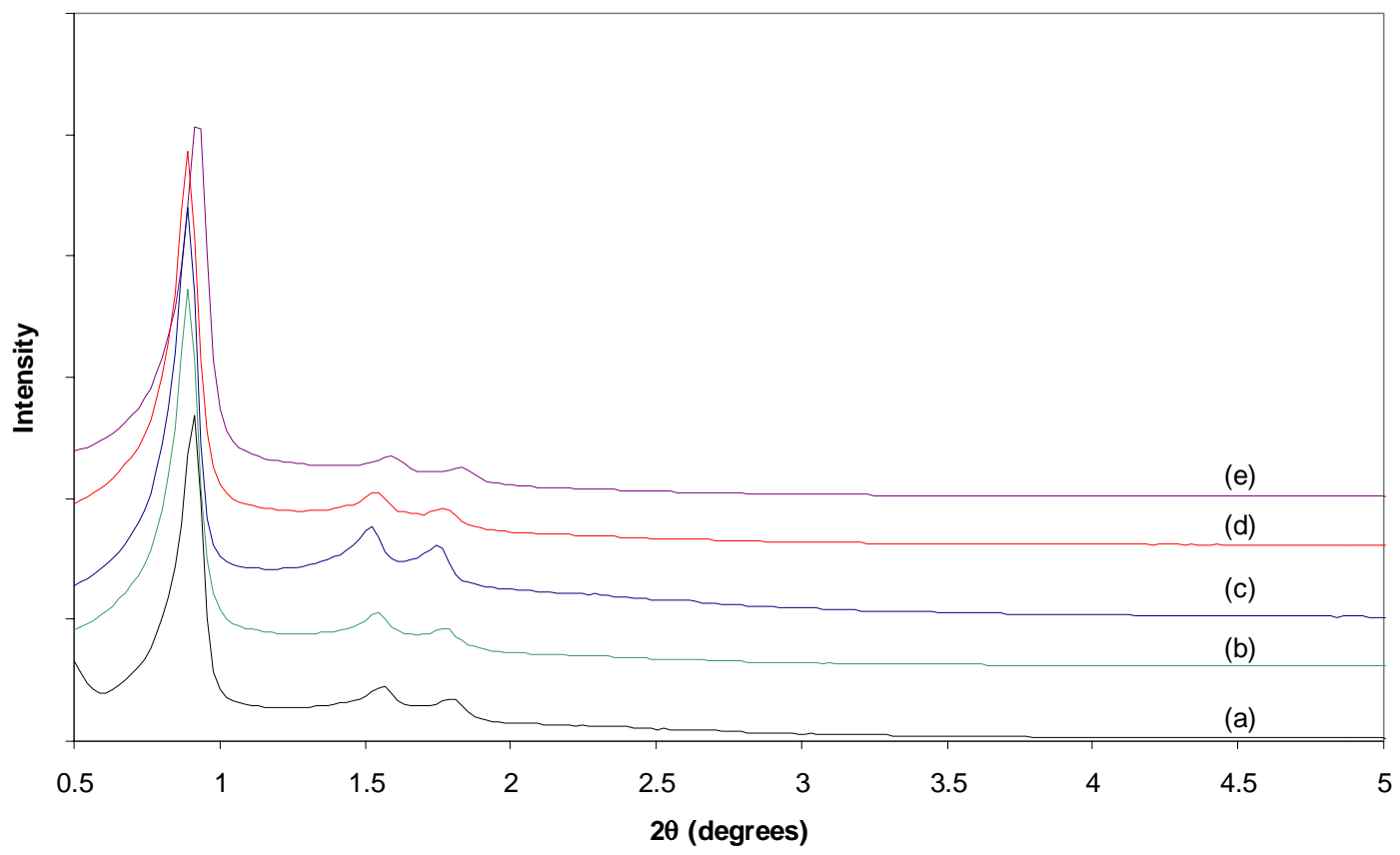

Figure S2. X-Ray Diffraction Patterns of functionalized SBA-15 materials. (a) SBA-15 (b) SBA-g1 (c) SBA-A (d) SBA-AT-p (e) SBA-AT-s5 


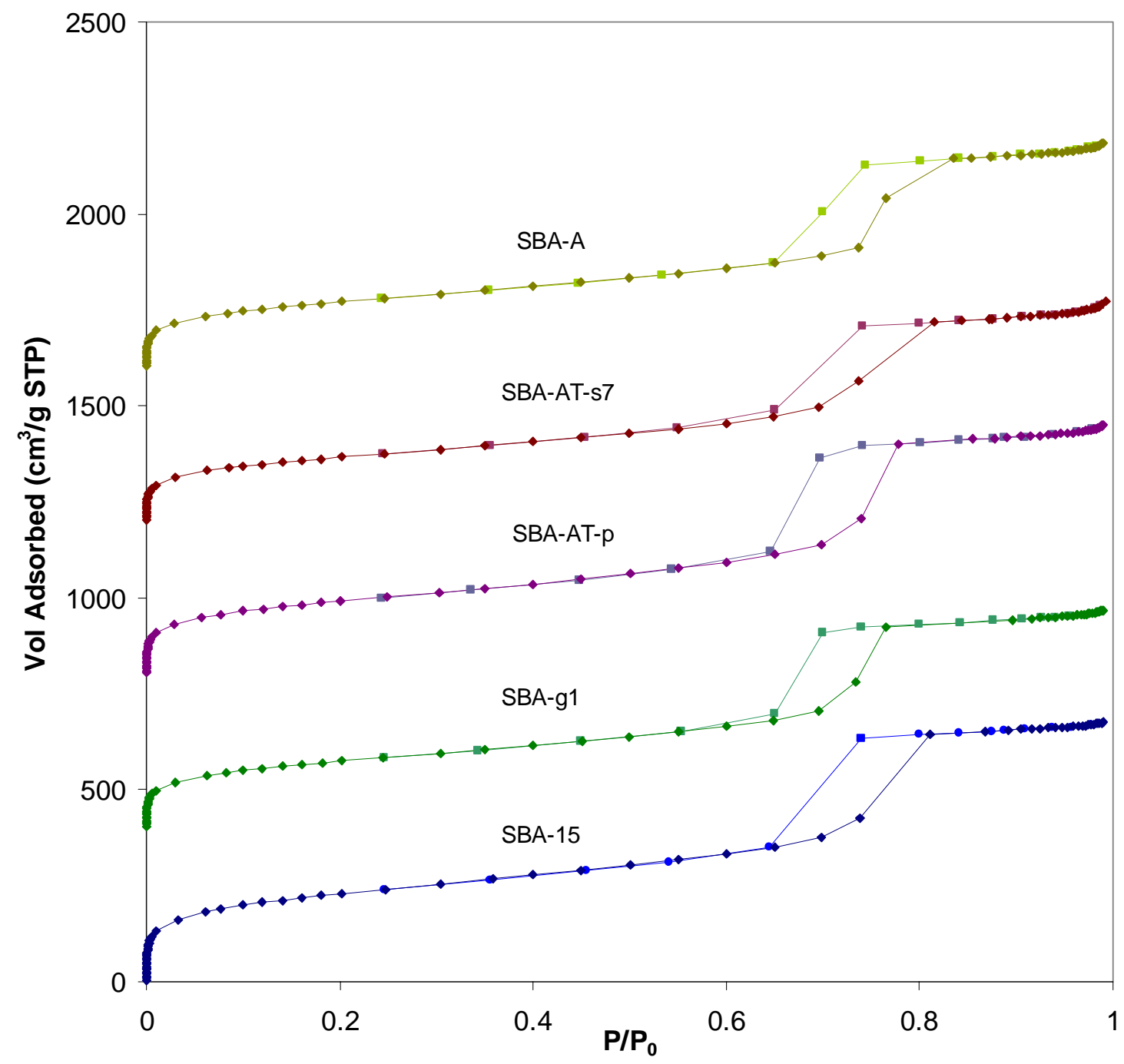

Figure S3. Nitrogen adsorption/desorption isotherms for various SBA-15 materials. Diamonds correspond to adsorption, squares to desorption. Data have been offset vertically by 400 units for clarity. The organic loading of each functionalized material is $\sim 0.2 \mathrm{mmol} / \mathrm{g}$. 


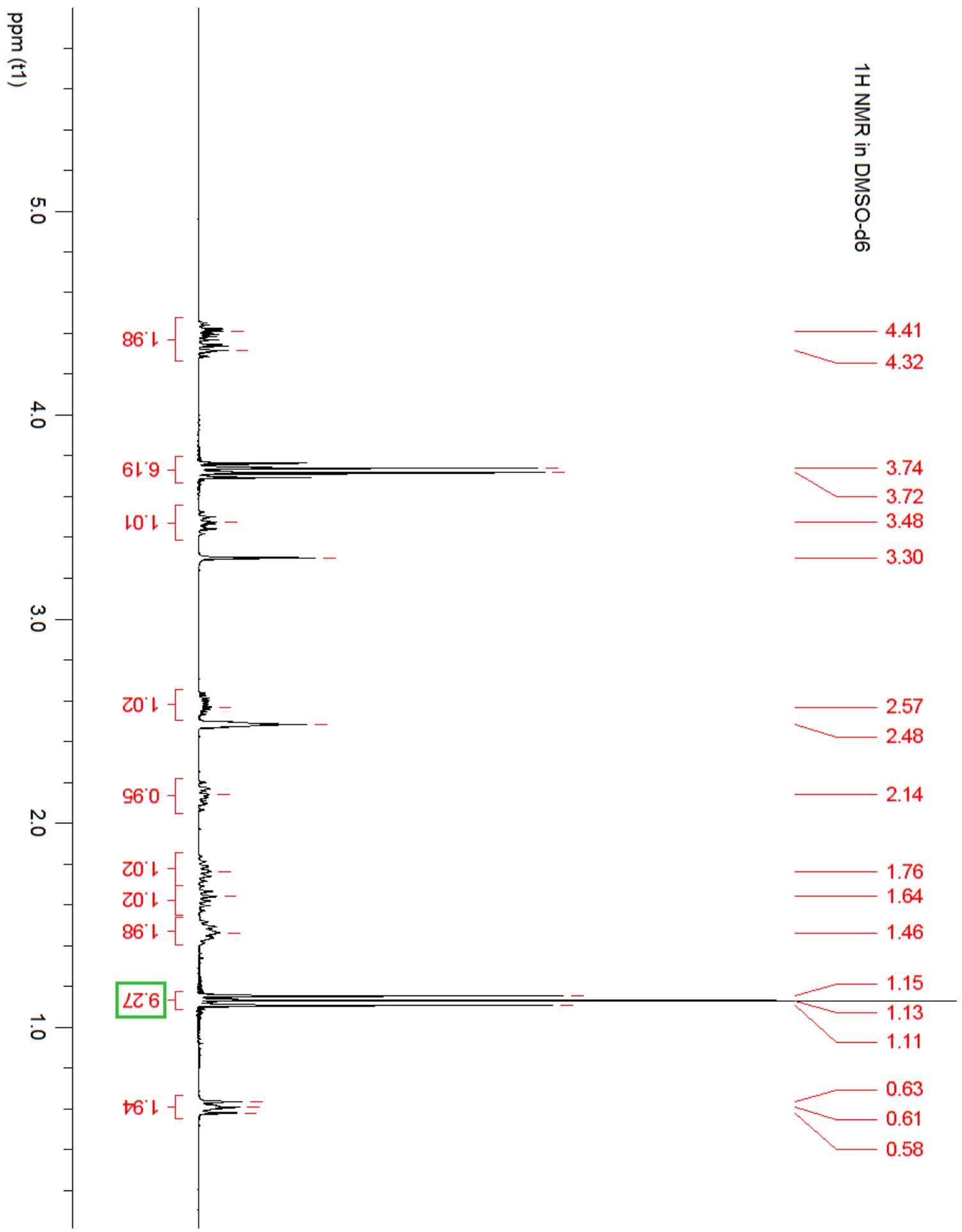

Figure S4. ${ }^{1} \mathrm{H}$ NMR spectrum of silane 1. Peaks at 3.30 and $2.48 \mathrm{ppm}$ correspond to $\mathrm{H}_{2} \mathrm{O}$ and DMSO respectively. 


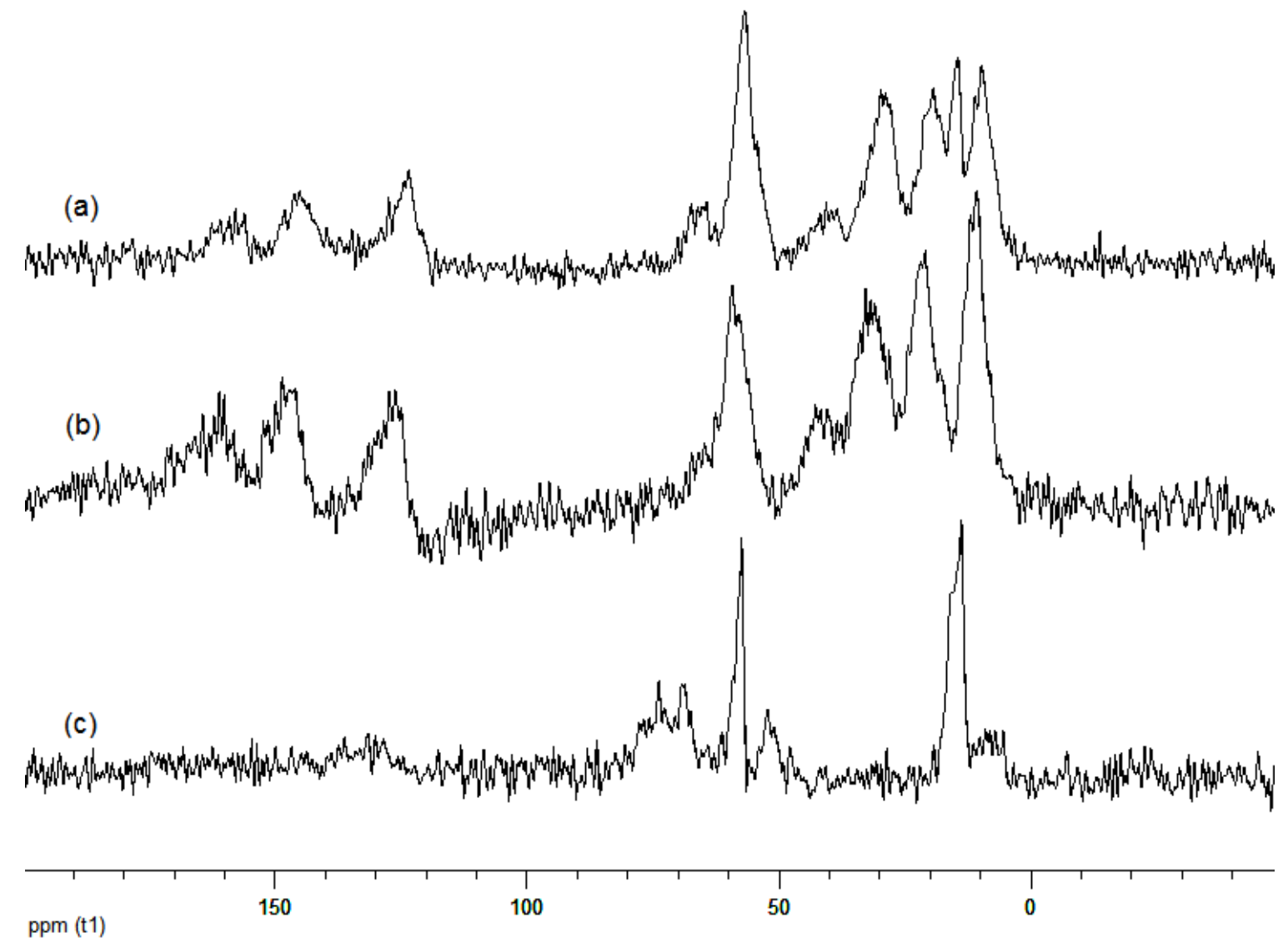

Figure S5. ${ }^{13} \mathrm{C}$ CP/MAS NMR spectra of randomly grafted materials. (a) SBA-15 grafted with silanes $\mathbf{1}$ and $\mathbf{2}$ (b) after hydrolysis (c) after disulfide reduction (SBA-ATr) 

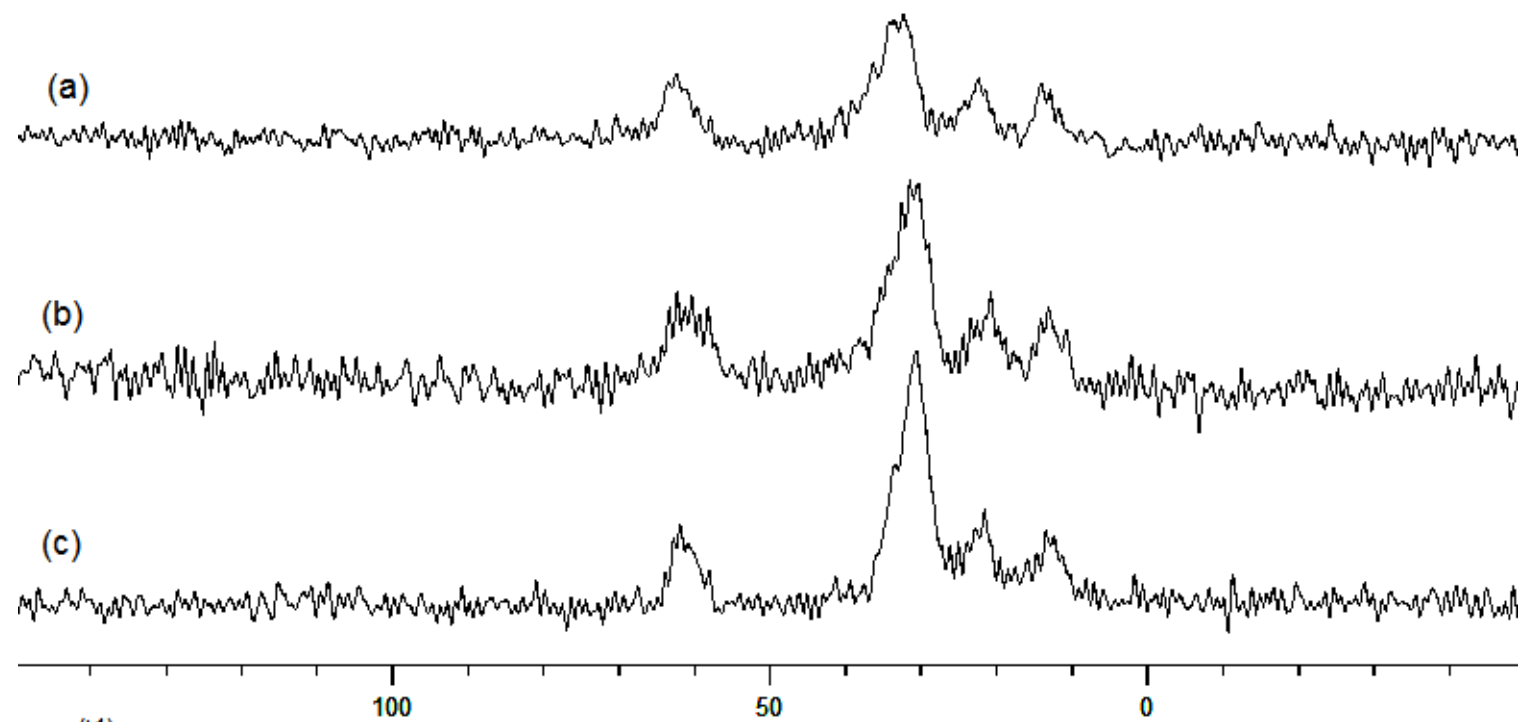
ppm (t1)

Figure S6. ${ }^{13} \mathrm{C}$ CP/MAS NMR spectra of alkyl spacer materials. (a) SBA-AT-s1 (b) SBA-AT-s2 (c) SBA-AT-s3 


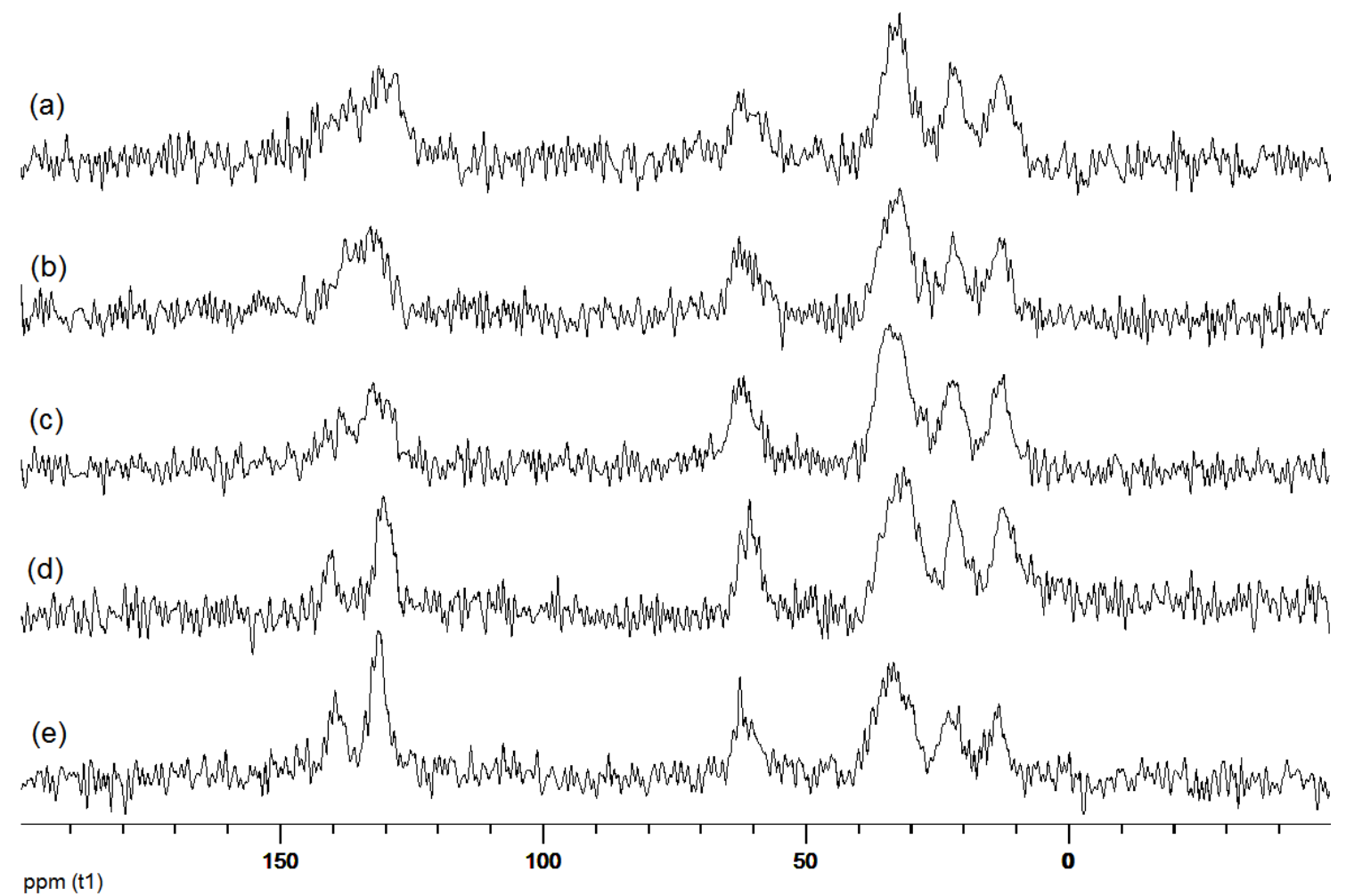

Figure S7. ${ }^{13} \mathrm{C}$ CP/MAS NMR spectra of aryl spacer materials. (a) SBA-AT-s4 (b) SBA-AT-s5 (c) SBA-AT-s6 (d) SBA-AT-s7 (e) SBA-AT-s8 